\title{
POLÍTICA E HISTORIA: RAFAEL BARRETT Y UNA TERCERA MIRADA EN LAS POLÉMICAS SOBRE EL PASADO Y EL PRESENTE EN EL PARAGUAY DEL NOVECIENTOS
}

\author{
Politics and history: Rafael Barrett and a third view on the politics about the \\ past and the present in the Paraguay of the nine hundred
}

Carlos Castells*

\section{Resumen}

El objetivo de este trabajo es realizar un acercamiento a una "tercera mirada" en las polémicas político-intelectuales producidas en la primera década del siglo XX en el Paraguay, que tuvieron como eje la "historia nacional" pero también la situación presente del país. A las dos narrativas dominantes, construidas desde la élite cultural y política, se le opuso una voz disonante -la del anarquista español Rafael Barrett-, que se ubicaría como una tercera posición en la discusión, impugnando aquellas al considerarlas como diferentes manifestaciones de la misma clase dominante, asumiendo contrariamente un compromiso histórico y político con los oprimidos.

$<$ Polémicas $><$ Intelectuales $><$ Rafael Barrett $><$ Historia nacional $><$ Anarquismo $>$

\begin{abstract}
The objective of this work is to analyze a "third point-of-view" on the politicalintellectual polemics produced in the first decade of the 20th century in Paraguay. These polemics were centered not only on the "national history" but also on the present situation of the country. The two dominant narratives were constructed by the cultural and political elite, to which the dissonant voice of the Spanish anarchist Rafael Barrett was opposed. Barrett's voice would be considered a third position in the discussion, assuming - in opposition of the two others- a historical and political commitment with the oppressed people.

$<$ Polemics $><$ Intellectuals $><$ Rafael Barrett $><$ National history $><$ Anarchism $>$

Recibido: 10/07/2018 // Aceptado: 25/09/2018

\footnotetext{
* Instituto de Investigaciones sobre el Lenguaje, la Sociedad y el Territorio (INILSyT), Universidad Nacional de Formosa (UNaF), Argentina. Becario doctoral del Consejo Nacional de Investigaciones Científicas y Técnicas (CONICET), carles1205@hotmail.com
} 
Castells. Política e Historia: Rafael Barret y una tercera mirada en las polémicas sobre el pasado y el presente en...

El hecho es que el affaire López continúa y continuará
siendo la encrucijada en que se encuentran, vibran y chocan
las opiniones fundamentales en el Paraguay; el foco donde
se juntan y comparan los diversos tintes de la controversia
pública, iluminándose unos a otros; el punto de partida para
rumbos políticos y hasta psicológicos. Según se interprete
a López se interpretan, en este país concentrado, en que
cualquier heterogeneidad se manifiesta veloz e intensamente,
una infinidad de conceptos al parecer remotos, como por
ejemplo el patriotismo. López es el tópico nacional.
Rafael Barrett, 1907

Como lo han planteado muchos autores e investigadores (sobre todo extranjeros, y muchos de ellos con asombro), la historia ha sido la "estrella" en las discusiones políticas y culturales en el Paraguay. La memoria histórica se hace presente en la cotidianeidad de la vida social y política del país, y en los más nimios sucesos políticos se asoma la discusión sobre la historia nacional y emergen a la superficie viejas discusiones, viejas rivalidades, antiguas polémicas, que parecen reflotar ante cada debate políticointelectual, mostrando la gran fuerza que todavía tiene determinado uso político del pasado $^{1}$. Esta presencia indiscutible de la "historia" en la escena política del país, sin embargo, durante mucho tiempo no generó una abundante bibliografía científica, y la producción historiográfíca académica fue, en general, pobre² .

Mucho más abundante, por el contrario, fue la producción ensayística, mayormente elaborada en contextos de "ardientes polémicas" y enconados debates políticos. Estas producciones, aunque escasamente apoyadas en bases documentales (o, en el mejor de los casos, apoyadas siguiendo el modelo probatorio-acusatorio sin preocuparse por la problematización de las mismas), establecieron líneas interpretativas de gran difusión que, en algunos casos, continúan presentes, incluso vigentes, en la actualidad.

\footnotetext{
${ }^{1}$ Cabe aclarar que, más que cualquier otro acontecimiento de la historia paraguaya, lo que sigue presente en la memoria histórica de sus habitantes es el drama central de la misma: la guerra de la Triple Alianza (1865-1870). Si bien el caso paraguayo no deja de formar parte de los "usos del pasado" presentes desde hace tiempo en la sociedad occidental, es difícil encontrar un caso de "historia en tiempo presente", como la denomina Luc Capdevila, que nos lleve a más de un siglo atrás, y sin la presencia de testigos directos con vida. Esta "presencia" de la guerra en el presente es una característica que singulariza el caso paraguayo. Capucine Boidin (2006), investigadora francesa que analizó la memoria oral popular sobre la misma, realizando un trabajo de campo en comunidades rurales guaraní-parlantes, sostiene que aquella aparece como el "mito de origen" o el "cráneo" del que provienen los mitos de la identidad nacional paraguaya. Al mismo tiempo, sigue presente como una especie de "trauma" colectivo, que engendra culpabilidad, remordimiento y silencios, y que el pueblo paraguayo no ha podido superar; como si se tratara de un "duelo" que no ha terminado de hacer. En consecuencia, no resulta extraño que la historia de la guerra haya estado presente en las producciones literarias, artísticas, etc. del país. En el caso de la literatura, véase Mar Langa Pizarro (2006), en especial la primera parte "La historia imposible".

2 Para un panorama del estado de la producción historiográfica paraguaya, que ha repuntado en los últimos años, véase Telesca (2013).
} 
El filósofo Darío Sarah (2011), en el prólogo al libro del intelectual paraguayo Mauricio Schvartzman, agrupaba las líneas interpretativas de la profusa producción histórico-ensayística paraguaya (a las cuales denomina "matrices narrativas") en dos grandes grupos: la matriz liberal-positivista, que aquí también llamaremos "cretinista", y la matriz romántico-nacionalista. Ambas "matrices narrativas" construyeron representaciones e imaginarios que se transformaron, siguiendo ese orden cronológico, en las dominantes en la vida político-ideológica del Paraguay. Su éxito y difusión fue tal que, salvo pocas excepciones, lograron clausurar la posibilidad de otros relatos, heterogéneos, diversos, que contemplaran otros actores sociales y que tuvieran en cuenta otros compromisos políticos y sociales (11-13). Una de las excepciones que escaparon a la etiqueta en una u otra de las dos narrativas dominantes fue la obra del escritor y pensador anarquista Rafael Barrett (1876-1910), español de origen y radicado en Paraguay en aquellos años. Consideramos, y lo intentaremos expresar en este artículo, que su propuesta fue antagónica a las dos anteriores, en tanto optaba por una defensa de los oprimidos, del pasado y del presente, e impugnaba el carácter elitista de aquellos discursos históricos.

Se trata de una serie de polémicas políticas e históricas protagonizadas por intelectuales, tal como se los define en el ya clásico trabajo de Altamirano (2008). Tanto O’Leary como Domínguez, Barrett o Báez participaban de los mismos espacios culturales -revistas, periódicos, instituciones educativas- con un público más o menos definido y su intención era "producir y transmitir mensajes relativos a lo verdadero (o si se prefiere: a lo que ellos creen verdadero) se trate de los valores centrales de la sociedad o del significado de su historia, de la legitimidad o la injusticia del orden político" (14-15). Sin embargo, y sobre todo en el caso de Barrett, pero no sólo en él, se trataba de ir más allá del círculo "letrado" (la prensa, los libros, la imprenta) para trasmitir su mensaje a otros sectores sociales: de allí su participación en las conferencias populares, organizadas por el naciente movimiento obrero paraguayo. De esta manera, Barrett intentó (y según sus propios balances, no siempre lo logró) salirse del espacio de los intelectuales burgueses apelando y vinculándose a los oprimidos, al pueblo trabajador, a los desheredados en general ${ }^{3}$. En este sentido, aunque el público de estos debates era un sector "letrado" bastante restringido, cabe la misma advertencia de Altamirano, de que "el intelectual no tiene una sola audiencia, un sólo público", y que, más allá de su propio espacio de disputa, sus criterios de relevancia no son los mismos para otras de sus posibles audiencias (14). En todo caso, no existen trabajos acerca de las formas de circulación y, más aún, de recepción de estos escritos, y nos referimos especialmente a un número pequeño pero creciente de obreros interesados en la formación intelectual y política, en la que destacarían los tipógrafos ${ }^{4}$, para los cuales Rafael Barrett sería un

\footnotetext{
3 "Tristezas de la lucha", artículo escrito en Germinal, Nro. 5, el 30 de agosto de 1908 (recopilado en Rafael Barrett, 1978, véase bibliografía), es uno de los más destacados balances que Rafael Barrett hace de su lugar de "intelectual rebelde" y de sus vínculos con "los de abajo". Uno de los balances que siempre mencionada a su camarada José G. Bertotto, coeditor de Germinal, era la falta de lectores obreros (Martínez, 2018).

${ }^{4}$ Con un trabajo calificado y vinculado a la palabra escrita, y expuestos a la circulación de ideas, los
} 
Castells. Política e Historia: Rafael Barret y una tercera mirada en las polémicas sobre el pasado y el presente en...

referente indudable 5 . Por lo tanto, no estamos en condiciones de reconstruir el impacto que la obra barrettiana tuvo en dichas polémicas, salvo, como veremos, en la reacción de las élites culturales dominantes.

Enmarcado dentro de la "historia intelectual", pues, este trabajo está divido en tres partes. En primer lugar, abordaremos la conformación de las dos matrices narrativas dominantes, y su contraposición en la polémica de 1902, entre Cecilio Báez y Juan E. O'Leary, en donde confrontarían las dos miradas que la élite paraguaya construiría sobre el pasado. No nos detendremos en profundidad allí, ya que consideramos que dicha polémica ya ha sido recuperada y analizada exhaustivamente en varios trabajos historiográficos (Brezzo, 2008; Orué Pozzo, 2008). En segundo lugar, en la parte fundamental de este trabajo abordaremos la propuesta de Barrett, que consideramos antagónica a las dos anteriores y original, en tanto rechazaba las tesis cretinistas como la idealización conservadora y patriótica. Finalmente, cerraremos con una conclusión y balance de los aportes de este trabajo.

\section{De las tesis cretinistas a la idealización patriótica: el pasado y el presente según la élite paraguaya}

La matriz liberal-positivista fue la primera en gestarse en el Paraguay de la posguerra. Situándose dentro del espectro de interpretaciones de corte positivista, con un muy marcado toque spenceriano y "mitrista" (como los acusarían sus detractores), la matriz narrativa liberal sobre la historia paraguaya se impondría una vez finalizada la guerra de la mano de la nueva dirigencia política que llevaría adelante los destinos del país en las siguientes décadas. Formada por una fusión conflictiva de legionarios ${ }^{6}$ y antiguos "lopistas", esta nueva élite política debió legitimarse en el poder procediendo al rechazo absoluto del gobierno anterior, considerado no sólo responsable de la guerra sino expresión máxima de la "barbarie" y la "tiranía", ideas que justificaban el enfrentamiento. Ubicados dentro de la lógica civilizatoria sarmientina, los dirigentes políticos de la posguerra procedieron a la desvalorización del pueblo paraguayo

tipógrafos siempre destacaron en la organización del movimiento obrero en muchos países, incluido el Paraguay (Gaona, 2008).

5 En 1912, un grupo de obreros y militantes tipógrafos fundarían el Centro de Estudios Sociales Rafael Barrett, el primero (y único por mucho tiempo) en el Paraguay. Con el tiempo, destacarían especialmente en la difusión de las ideas barrettianas dos tipógrafos de larga trayectoria sindical en el Paraguay, como el socialista Rufino Recalde Milesi (1885-1957) y el anarquista Ciriaco Duarte (1908-1996).

6 La llamada "Legión Paraguaya" fue un batallón armado impulsado por la "Asociación Paraguaya", agrupación política de los exiliados paraguayos en Buenos Aires a mediados del siglo XIX. Participaron en la guerra peleando por el bando aliado, y como tal, la memoria histórica paraguaya los recuerda como traidores. Muchos de ellos, proveniente de familias patricias de Asunción, ocuparon roles destacados conduciendo los hilos del país al fin de la guerra. Con el paso del tiempo, con la hegemonía del discurso nacionalista en la política paraguaya, el uso político de la palabra se extendió con el significado de "vendepatria", anti-paraguayo, traidor, etc. El caso de la palabra "legionario" es similar, salvando las distancias, al término "cipayo", usado en la política argentina. Para más información, véase Fuentes Armandans (2016). 
asumiendo de esta manera la justificación que el bando vencedor había venido construyendo desde el comienzo de esta ${ }^{7}$.

Fue así como surgieron las "tesis cretinistas", que planteaban la historia paraguaya como una sucesión de gobiernos tiránicos, cuyo corolario trágico sería la megalómana dictadura de Francisco Solano López, sostenidos a su vez por un pueblo "cretino" que, con pasiva resignación, cual un rebaño temeroso, se hubo aplacado bajo los mismos ${ }^{8}$. El pueblo paraguayo, gobernado por la tiranía colonial y jesuita primero, y luego por la tiranía de Francia y los López, fue acostumbrado a vivir bajo el yugo vigilante de los gobernantes de turno, incapaz de asumir las responsabilidades cívicas y de disfrutar de los beneficios de la "civilización". En una de las primeras manifestaciones de esta línea interpretativa, José S. Decoud (1877) planteaba las características del pueblo paraguayo:

Nuestro pueblo es tradicionalmente indolente por más que se diga lo contrario. Los hombres de la campaña son muy poco afectos al trabajo y prefieren en su mayor parte la vida haragana ó vagabunda; son las mujeres las que se entregan regularmente á las faenas agrícolas, mientras que el hombre duerme tranquilamente la siesta. Esta indolencia natural es característica de nuestra raza desde los tiempos mas remotos (...) durante el largo reinado de la tiranía fue necesario dictar medidas rigurosas para obligar á los naturales á hacer plantaciones de árboles frutales como el naranjo, la banana etc. y sembrar tabaco, algodón y otros productos $(1877,4)$.

Esta "indolencia natural” debía ser combatida, y el pueblo paraguayo debía de ser "civilizado" mediante el fomento de la inmigración europea, fuente del progreso moral

7 Si bien trabajos recientes demuestran que la memoria histórica del Paraguay de la posguerra estaba lejos de ser "unánime" (Brezzo: 2015, 73), sostenemos que sí hubo un "relato oficial" claramente identificado con los ganadores de la contienda. En términos jurídico-legales, López fue considerado "enemigo del género humano" mediante decreto del gobierno provisorio en 1869 (y por ley del congreso, en 1871), y esta legislación sólo fue abolida en 1936, por el gobierno militar de Rafael Franco, más allá de un importante debate llevado a cabo en el Congreso en el año 1926 (Archivo del Liberalismo, 1988). Por otro lado, el primer libro de texto de historia paraguaya de uso oficial en las escuelas, escrito por de Leopoldo Gómez de Terán y Próspero Pereira Gamba en 1878, basándose en autores extranjeros o en escritos de miembros destacados de la élite paraguaya de posguerra, claramente se encuadraba dentro de dicha visión. Como plantea David Velázquez Seiferheld (2015): "es claro que esta versión de la historia es la de los vencedores, los mismos que habían declarado en 1871 al Mariscal López fuera de la ley, desnaturalizado, asesino de su patria y enemigo del género humano y los que habían decretado en 1870 que se celebrase como feriado el 25 de mayo de la independencia argentina" (97). Las críticas al libro de Terán y Gamba se harían más fuertes con el correr del tiempo, y con el cambio de siglo sus días estaban contados, ante el avance de una educación más "patriótica".

8 "Cretino" es utilizado aquí, y en todas las menciones siguientes y relacionadas, en el sentido que le dieron los pensadores liberales, como sinónimo de "autómata", es decir, un ser que ha caído en una situación de "heteronomía", perdiendo su autonomía ante el "tirano" (véase las citas de Báez, en las siguientes páginas de este mismo trabajo). De esta manera, los paraguayos, ya sean considerados negligentes o víctimas inocentes, son igualados, no obstante, a un rebaño sin voluntad ni capacidad de discernimiento. 
Castells. Política e Historia: Rafael Barret y una tercera mirada en las polémicas sobre el pasado y el presente en...

y material, que ayudaría a "transformarlo". Decoud también mencionaba la persistencia de prácticas autoritarias que impedían el progreso material del campo paraguayo. No se trataba, entonces, de una cuestión racial o biológica (como se plantearía en otras partes del continente, y como dejaría planteado el mismo Sarmiento en sus referencias al Paraguay $^{9}$ ), sino de problemas que encontraban sus raíces en la propia historia del país.

La principal exposición de las “tesis cretinistas” la llevaría adelante el Dr. Cecilio Báez (1862-1941), importante intelectual, político y diplomático paraguayo, miembro a su vez del ala radical del Partido Liberal, partido que a fines del siglo XIX y hasta 1904 se encontraba en la oposición. En su larga carrera intelectual y política se desempeñaría en diferentes cargos, llegando a Rector de la Universidad Nacional en varios períodos e incluso, asumiendo la presidencia de la República, de manera provisoria entre diciembre de 1905 y noviembre de 1906. Tras llegar de una misión diplomática en México, en mayo de 1902, Báez escribiría una serie de artículos en el periódico El Cívico, órgano liberal, sobre temas económicos, en especial denunciando el mal manejo de las finanzas públicas y las falsas informaciones oficiales, que pretendían mostrar que la economía del país iba bien encaminada. Precisamente, en uno de esos artículos, se iniciaría la principal polémica que marcaría los dos grandes discursos históricos en el Paraguay ${ }^{10}$. El desencadenante sería un fragmento, en donde Báez señalaba:

El Paraguay es un pueblo cretinizado por secular despotismo y
desmoralizado por treinta años de mal gobierno. Cinco años de
titánica lucha pudieron retemplar sus adormecidas fibras por
el opio del despotismo. Por eso el pueblo paraguayo desplegó
cualidades cívicas en los comicios, a raíz de la conclusión de
la guerra; pero la disolución de las cámaras vino de nuevo
a matar el naciente espíritu público y he aqui que el pueblo
sigue siendo semejante a un cretino, a un ser sin voluntad ni
discernimiento (Báez \& O'Leary: 2008, 74).

El artículo tenía un trasfondo político bastante claro. Báez era un reconocido dirigente liberal, partido que, como dijimos anteriormente, se encontraba en la oposición y que ya comenzaba a conspirar para hacerse con el poder, cosa que lograría por la vía armada en 1904, es decir, dos años después. Pero la polémica se refirió casi exclusivamente a su tesis del "cretinismo del pueblo". La respuesta a Báez provino de un joven intelectual y periodista llamado Juan O’Leary, quien se venía desempeñando

\footnotetext{
9 La más famosa de las apreciaciones sarmientinas sobre los paraguayos como parte de la raza inferior indígena ("descendientes de guaraníes") está en la carta a Mitre de 1872, citada innumerables veces en la historiografía revisionista como ejemplo de sus ideas genocidas a favor de la matanza indiscriminada (El Nacional, 12 de diciembre de 1877). En la misma línea se mantenía en 1883, cuando publicaría "Conflictos y armonía de razas en América" (Sarmiento, 1915 [primera ed. 1883]).

${ }^{10}$ Como parte de una enorme labor llevada adelante desde hace tiempo, la polémica fue reeditada en 2008 por la editorial Tiempo de Historia, con estudio introductorio de Liliana Brezzo (2008). Al mismo tiempo, se han reeditado Escritos Selectos de Báez (2013), Recuerdos de gloria de O'Leary (2008) y El alma de la raza de Domínguez (2009). En el caso de Barrett, la mayor parte de su obra fue reeditada varias veces desde 1911, destacándose la edición paraguaya de sus Obras Completas, por RP Ediciones, entre 1988-1990.
} 
como profesor de historia en el Colegio Nacional de Asunción, además de llevar adelante una serie de publicaciones en el diario La Patria, órgano vinculado al oficialista Partido Colorado" ${ }^{11}$ que bajo el título de "Recuerdos de gloria", recuperaba acontecimientos de la guerra con el objetivo de recordar "el heroísmo de nuestros padres" en virtud de recuperar el ánimo abatido de los compatriotas y recuperar, de esta manera, "la memoria de aquellos que hoy duermen casi olvidados de la patria historia, después de haber escrito en sangre la estupenda epopeya de aquella defensa sobrehumana" (O'Leary: 2008, 15). Obviamente, O’Leary denunciaba las tesis cretinistas de Báez, considerándolas "deshonrosas" proviniendo de un paraguayo que despreciaba a su propio pueblo, y se planteaba el objetivo de defender el "honor mancillado" de la patria. Y así, poco a poco, la polémica se fue desarrollando en la prensa por varios meses, derivando hacia dos visiones opuestas del pasado paraguayo, con particular énfasis en el drama central de su historia: la guerra contra la Triple Alianza.

Los artículos de Cecilio Báez, todos publicados en El Cívico y compilados apenas terminada la polémica bajo el título de Tiranía en el Paraguay: sus causas, caracteres y resultados (1903), se convertirían en la máxima expresión de la interpretación liberalpositivista de la historia paraguaya. Resumidamente, en los mismos, Báez (1903) sostendría que la guerra no sólo fue obra de los aliados sino consecuencia de la tiranía paraguaya, heredera de la barbarie colonial, agregando que ésta había generado un pueblo "cretinizado" y que ahora era necesaria la tarea de sanar las heridas: "toca a la nueva generación reparar lo perdido, por la educación, por el trabajo, por la práctica de la libertad, por el concurso del elemento extranjero, pero principalmente por la educación, para que al rebaño humano lo reemplace un pueblo consciente de sus derechos, que haga imposible la vuelta de las omnímodas y embrutecedoras dictaduras" (1903, 49-51).

Las ideas cretinistas se enmarcaban claramente en una agenda política bastante concreta. Aunque denunciaban las prácticas autoritarias y el estado miserable de la situación económica, la denuncia moralizadora y catequizadora no reconocía un problema social de fondo. Todo se reducía a malos gobernantes y cretinos o "autómatas" que debían ser educados cívicamente. En este sentido, las ideas cretinistas resultaban funcionales a una prédica que servía de legitimación de las políticas privatizadoras al servicio de los inversores y empresarios extranjeros que se habían instalado en el país. Con palabras parecidas, en boca de políticos y empresarios ${ }^{12}$ se justificaba la expropiación de las masas rurales, incultas y bárbaras, consideradas incapaces de ahorro

\footnotetext{
${ }^{11}$ Durante el gobierno de Bernardino Caballero (1880-1886), héroe de guerra paraguayo que combatió junto a López casi hasta el final, se produce la gran escisión política de la dirigencia paraguaya de la posguerra. En 1887, una parte de la juventud y de los intelectuales rompen con el gobierno denunciando la corrupción y el "caciquismo" y deciden formar el "Centro Democrático", luego reorganizado como Partido Liberal. Los oficialistas, ese mismo año, se organizan a su vez en el Partido Nacional Republicano. En poco tiempo, como en muchos otros casos en el continente, ambos bandos adoptarían un color distintivo: los liberales el azul, los republicanos el rojo. Con el tiempo, los republicanos pasarían a ser conocidos como "colorados", y su asociación, como Partido Colorado.

${ }^{12}$ Más arriba mencionamos a Decoud, pero las ideas acerca de la "incapacidad" de los paraguayos para el trabajo, era muy frecuente: políticos, curas, observadores y encargados de negocios extranjeros, etc. (Véase Rivarola, 2010 y Kleinpenning, 2014).
} 
Castells. Política e Historia: Rafael Barret y una tercera mirada en las polémicas sobre el pasado y el presente en...

y creación de riqueza, y se fomentaba contrariamente la colonización y el aporte del capital extranjero, los encargados de llevar adelante la obra "civilizatoria" en el país. Los paraguayos, para poder integrarse a esta nueva sociedad debían "civilizarse" y dejar de ser un "rebaño" al servicio de los tiranos de turno. Pero la educación cívica y la "práctica de la libertad" tenían sus límites: una vez como presidente en 1906, el mismo Báez dejaría bien claro que "el guiñapo rojo del anarquismo" no era bienvenido en el Paraguay (Báez, 1906).

En la orilla opuesta, como dijimos, se encontraba Juan O’Leary (1879-1969). Mientras Báez era un reconocido y experimentado intelectual ya consagrado para principios de siglo, más cercano en su formación a la generación liberal de la inmediata posguerra, O’Leary era un joven miembro de la llamada generación del novecientos o "novecentista" (Amaral, 2006). Se trataba de una camada de intelectuales paraguayos jóvenes, la mayoría nacidos después de la guerra, que serían los principales protagonistas de las fuertes polémicas desatadas en la primera década del siglo XX, siendo partícipes de la febril actividad cultural y política desarrollada en la prensa de aquellos años. Destacarían entre muchos, Arsenio López Decoud, Manuel Domínguez, Manuel Gondra, Fulgencio R. Moreno, Blas Garay, Eligio Ayala, Juan E. O’Leary e Ignacio A. Pane. "En 1895 este núcleo de jóvenes novecentistas, junto a otras figuras influyentes de la sociedad asunceña, fundaron el Instituto Paraguayo, un espacio cultural en el que la fuerza de la palabra se convertiría en fuente de prestigio" (Brezzo: 2010, 109). Este Instituto sería el principal espacio cultural del Paraguay del novecientos. En 1896 fundaron la Revista del Instituto Paraguayo, publicación de carácter "científico", dónde la preocupación fundamental, sin embargo, fue la histórica y literaria.

En este contexto, pues, es que se desarrolló la polémica. O’Leary criticaba los textos de Báez desde el diario La Patria, dirigido nada menos que por Enrique Solano López, hijo de Francisco Solano López, el "tirano" en cuestión. Ambos adscribían, además, al Partido Colorado, en ese entonces en el gobierno. Desde dicho diario, O’Leary redactó una serie de artículos bajo el irónico título de "El cretinismo paraguayo", en donde replicaría las tesis de Báez. Apuntaría eficazmente contra las principales debilidades de su contrincante: sus contradicciones en torno a la figura del Dr. Francia (realzado por Báez en 1886, y después demonizado), sus erróneas apreciaciones sobre el fomento de la educación en la era de los López y, finalmente, sobre el "deshonroso" desprecio hacia una gesta heroica sin igual como la de la Guerra Grande. O’Leary, terminantemente, acusaría a Báez de seguir una línea interpretativa "anti-paraguaya" (de "amar a la Argentina") y arrodillarse ante Mitre, "el único verdugo de nuestra patria” (Báez \& O’Leary: 2008, 234).

En cuanto al problema de la “tiranía”, aunque O’Leary reconocía estar en contra, quedaba en un segundo plano en su argumentación. Ésta se centraba fundamentalmente en la "epopeya patriótica"; apuntaba a exaltar el heroísmo del pueblo paraguayo y recuperar la memoria de sus héroes de la generación pasada, condenando a su vez la operación "infamante" de Báez, que transformaba en "cretinos" a los protagonistas de la gesta heroica que pensaba reivindicar: 
Sólo en nuestro país no se sabe ahogar los viejos odios, para hacer justicia a la causa nacional. Sólo aquí se trata de infamar, de llenar de lodo el inmenso sacrificio de nuestro heroico pueblo. Decir que López provocó la guerra, metiéndose como un imbécil en la cuestión oriental, es probar que los paraguayos eran verdaderamente cretinos, acompañando en cuerpo y alma a su gobierno, en aquella partida de imbecilidad, y es también negar toda gloria a nuestro ejército, porque la gloria ni la pueden alcanzar los seres sin voluntad ni discernimiento, ni es posible en la defensa de una mala causa (Báez \& O'Leary: 2008, 408).

En su discurso, O'Leary crearía un pasado heroico y glorioso, en el que la sociedad paraguaya vivía feliz y próspera hasta que las maquinaciones del Imperio del Brasil y del gobierno argentino de Mitre conformaron "la mano negra que arrojó, sobre el Plata y el Paraguay, el huracán de muerte que hizo añicos de nuestra pasada grandeza y poderío" (Báez \& O'Leary: 2008, 370).

Cabe aquí, como paréntesis, destacar que tanto en Báez como en O’Leary no existió el recurso a la documentación como prueba válida para refutar la interpretación del adversario. El recurso más utilizado, en cambio, fue la cita de autoridad, tratándose mayormente de autores extranjeros, recuperando en ambos casos las citas o comentarios que les sirvieran en su argumentación ${ }^{13}$. En todo caso, poco pareció importarles a los contrincantes lo que "objetivamente sucedió", sino más bien, en el caso de Báez, construir un relato que explique el "atraso" del Paraguay y su incapacidad de integrarse en la senda del progreso, y en el caso de O'Leary, poner "a salvo la Nación, ofendida y menospreciada" (Brezzo: 2008, 45).

Paralelamente a los artículos de O'Leary, otro intelectual contemporáneo entraría en la polémica en su apoyo. En enero de 1903, Manuel Domínguez, acompañaría la posición de su compañero del diario La Patria, en una conferencia realizada en el Instituto Paraguayo, titulada "Causas del heroísmo paraguayo". No se trataba de una persona cualquiera: Domínguez era el vicepresidente de la República desde 1902 y previamente había sido el Rector de la Universidad Nacional, su opinión tenía cierta autoridad y su intervención, siendo miembro del gobierno colorado, no era políticamente inocente.

Si bien recuperaban sucesos históricos, los argumentos de Domínguez (1903) apuntaron más bien a demostrar la superioridad del Paraguay como "nación" con respecto a los aliados, planteando que el Paraguay "era un pueblo feliz en su sencillez", naturalmente valiente y acostumbrado a sobrellevar pesadas cargas (y a "sufrirlas

\footnotetext{
${ }^{13}$ En muchos casos, tanto Báez como O'Leary citarían a los mismos autores. Para justificar sus afirmaciones sobre Francia y los López, Báez recurrirá a las fuentes clásicas como los hermanos Robertson, Rengger y Longchamps, Idelfonso Bermejo, Alfred Demersay y Juan C. Centurión; mientras que O'Leary recuperaría la obra histórica del político uruguayo Luis A. de Herrera (con quién iniciaría una larga relación de correspondencia. Véase Brezzo y Reali, 2018) y del argentino Juan B. Alberdi (quién defendió la posición paraguaya durante la guerra).
} 
Castells. Política e Historia: Rafael Barret y una tercera mirada en las polémicas sobre el pasado y el presente en...

callado"); era un pueblo compacto y homogéneo, con una sola voluntad y un solo sentimiento y que en el momento de la guerra se levantaría como un solo hombre, en fin

el Paraguay era superior al invasor como raza y en las energías que derivan de esta causa: en inteligencia natural, en sagacidad, en generosidad, en carácter hospitalario, hasta en estatura que dijo Azara, hasta en lo físico que dijo Thompson, en el número de hombres blancos que digo yo. Era un blanco sui generis, bravo, fuerte. Hubo unos pocos hombres de color en el Paraguay y en la guerra su inferioridad en empuje, en resistencia, se puso en evidencia: en los primeros choques sucumbieron (37).

Con Domínguez entramos, concretamente, en el plano de una justificación biologicista y racial, curiosamente construida de forma sui generis, original en muchos sentidos, a contramano de comoeran pensadas esas interpretaciones contemporáneamente, más en base a la "pureza racial" que al "mestizaje", en general interpretado negativamente por los autores. Para esta interpretación biologicista Domínguez recuperaba citas de autoridad -en su mayoría, otra vez, de autores extranjeros- sobre la capacidad física, la resistencia, el "espíritu combativo", los "rasgos superiores", etc., del pueblo paraguayo. Subvaloraba, como vemos, el aporte africano, en una marca que sería constante en los estudios históricos paraguayos. Esta obra político-ensayística marcaría un hito en el camino de la construcción del mito del mestizaje "armónico", de tanta influencia en el país. Según Domínguez (1903), el mestizaje hispano-guaraní habría producido, en su fusión, algo superior a dichos elementos separados: "el paraguayo, superior al porteño, superior al criollo, es también superior al español de Europa" $(1903,11)$.

Conviene agregar otra cuestión con respecto a Domínguez, en su idealización del Paraguay del siglo XIX, recuperaba una idea muy arraigada sobre el Paraguay colonial y republicano, y que trasladaba subrepticiamente al presente. Se trata de la supuesta "igualdad" entre los paraguayos, la inexistencia de una división en clases sociales: "Todavía en el Paraguay hay una igualdad que ha de asustar al aristócrata. Pi y Margall admiraba este nuestro modo de ser. No hay clases opresoras ni oprimidas. Ni la aristocracia del dinero se ha formado todavía. La raíz de esta democracia está, según se ha visto, en cierta profundidad de nuestra historia" $(1903,27)$.

Como queda expresado claramente, tanto O'Leary como Domínguez estaban empeñados en reivindicar los valores espirituales y hasta físicos de la "paraguayidad" mediante la exaltación caudalosa de los hechos y los hombres de la "epopeya nacional". Esta exaltación, consecuentemente, era deliberadamente extendida hasta el presente de la polémica. Al contrario de Báez, los novecentistas no consideraban paupérrima la situación del Paraguay del novecientos: dónde Báez veía atraso y barbarie, ellos veían "sencillez", dónde aquel veía "cretinos" o gente sin discernimiento, ellos veían un pueblo tranquilo y "varonil", acostumbrado a sufrir callado y a enfrentar el mundo con resignada valentía (Telesca, 2012). En las obras de O’Leary y Domínguez, no había crítica social alguna. Más bien al contrario, toda su argumentación procedía a la "idealización" romántica (y conservadora) del pueblo, de sus costumbres, de sus caracteres; en una apuesta por defender un "honor nacional" constantemente "agredido" por mitristas, cretinistas y, como veremos a continuación, por "extranjeros críticos". 


\section{Rafael Barrett: la voz disonante de la denuncia anarquista}

Construidos desde el poder político y la élite cultural, estos discursos eran funcionales, aunque de diferente forma, al statu quo. Estaban hechos a medida de la clase dominante y de sus proyectos políticos: tanto en la desvalorización como en la idealización del pueblo paraguayo, no se reconocía cuestión social ni opresión. De un lado, en el tono moralizador del intelectual positivista se denunciaba su falta de autonomía y su incapacidad e indolencia; del otro, paternalmente se idealizaba su situación y se enaltecía su resistencia. No obstante, a pesar de la abrumadora y avasallante difusión de estos, existieron otros relatos, construidos desde los márgenes que, aunque "acallados", permitieron otra mirada de la historia del Paraguay. Tal fue la propuesta de Rafael Barrett, la primera "voz disonante" que, desde posiciones libertarias propuso una tercera posición, alejada tanto del nacionalismo romántico de O’Leary y Domínguez como de las tesis cretinistas liberal-positivistas de Báez.

Rafael Barrett (1879-1910) fue un periodista e intelectual anarquista nacido en España, pero emigrado a América, terminando por llegar al Paraguay en 1904. En este país vivió por seis años, y allí produjo la mayor parte de su obra, conformada por artículos y "aguafuertes" publicados en la prensa diaria, tocando una variada gama de temas que iban desde cuestiones sociales, políticas, económicas y literarias del país, la región y el mundo. Fue en esta su nueva "patria" donde Barrett asumiría las ideas libertarias y se acercaría a las luchas del naciente movimiento obrero paraguayo, durante las cuales sufriría privaciones y estadías en la cárcel que repercutirían en el empeoramiento de su salud (estaba enfermo de tisis), lo que terminaría provocándole la muerte en 1910.

Cuando Barrett llegó al país, a mediados de 1904, éste se encontraba en plena "revolución" de 1904: insurrección armada que después de meses de lucha, llevaría al Partido Liberal al poder. Llegó como corresponsal del diario El Tiempo, de Buenos Aires, y se sumó rápidamente a las filas del ejército rebelde. Su primera nota, hecha para el periódico porteño casi sin conocer el país, mostraba claramente su adhesión a las tesis liberales cretinistas, predominantes en el bando rebelde, y denunciaba al Partido Colorado, como continuador de la "tiranía" anterior a la guerra: "Hasta en tiempo de paz han encontrado medios de satisfacer sus instintos bestiales los tiranuelos del Paraguay, y han sangrado en esclavos indefensos la apoplejía de ferocidad heredada de los Francia y de los López" (Barrett: 1990, 6014).

Estas ideas iniciales, fueron mutando rápidamente en los años siguientes. Debido a sus excepcionales cualidades intelectuales, Barrett se incorporó a la actividad cultural y literaria paraguaya. Trabajó en la Oficina de Estadística y en la administración del Ferrocarril, pero no duró mucho en dichos trabajos. Publicó artículos y crónicas en la prensa asuncena, y también se integró al Instituto Paraguayo, en cuya revista escribió una reseña (Año IX, No 56, 1907) sobre un libro de C. Báez ("Cuadros históricos y descriptivos del

\footnotetext{
${ }^{14}$ Como existen múltiples ediciones de sus Obras Completas, decidimos citar la más completa de dichas ediciones (la de ICI-RP Ediciones, 1988-1990). Como la referencia es muy lejana en el tiempo a los escritos, mencionamos los datos de la publicación original, en el cuerpo del texto. En el caso de los artículos posteriormente reunidos en el libro "El dolor paraguayo", citamos la primera edición del mismo, en 1911.
} 
Castells. Política e Historia: Rafael Barret y una tercera mirada en las polémicas sobre el pasado y el presente en...

Paraguay"), titulado "En torno al libro del Dr. Báez", donde hacía una expresa defensa de "la historia como vehículo de la política", y reivindicaba la "sincera y generosa parcialidad" del autor, su carácter propagandístico. Sin adherir a sus ideas, mencionando que Ignacio A. Pane o Juan E. O'Leary opinaban distinto, prefiere discurrir sobre el "affaire" López: entendía ya para entonces que en la polémica sobre su figura lo que se manifestaba era la oposición entre dos proyectos políticos de "construcción de la nación":

Se comprende que todo gire alrededor de ellos, que a partir de ellos se inaugure la existencia del Paraguay. Los orígenes comunes están a la vista y con energías apremiantes sugieren ideas, programas, ilusiones. Hay quien intenta, salvando la cima, buscar la nacionalidad amputada; otros, barriendo escombros, ensayan sobre la tabla rasa magnífica los flamantes recursos de la civilización (Barrett: 1990, 187).

Cabe señalar que Rafael Barrett no se distinguiría en cuanto a su forma de intervención en el debate histórico, recurriendo a la cita de autoridad y a opiniones que se ajustaban a sus posiciones político-intelectuales. Más aún, en su obra, encontramos una justificación de esta opción. Barrett fue un fuerte crítico del método histórico tradicional y un férreo defensor del ensayo político, como queda expresado en su reseña de Báez. En un artículo publicado en La Razón (Montevideo, 11 de mayo de 1910) expresaba sus ideas sobre la producción histórica. Desconfiaba de la pretendida "cientificidad" o "neutralidad" de la historia, y aunque consideraba importante la documentación, se burlaba de los historiadores de su tiempo, que atiborraban de citas documentales sus libros de historia, pensando que así podían borrar "nuestras pasiones, nuestros prejuicios, nuestros intereses". Para Barrett (1989), "la documentación es un pretexto para hacer historia, y la historia es un poema menos inverosímil que los otros" (28).

Las amigables referencias de los intelectuales liberales y novecentistas, arriba mencionadas, se extinguirían bastante rápido, una vez que comenzara sus denuncias sociales en la prensa. Perseguido por los gobernantes de turno, Barrett se iría alejando de sus amistades en la élite liberal y se vincularía a los dirigentes obreros anarcosindicalistas, produciéndose una profunda mutación al interior de su pensamiento. Los proyectos políticos de la élite liberal ya no le importaban, ahora su apuesta era la denuncia de la opresión, de la injusticia, y la denuncia del latifundio, de la "esclavitud" y de la miseria. Sus preferencias también habían cambiado. Su reivindicación de la política y el progresismo liberal de los primeros tiempos había dado lugar a un fuerte apoliticismo y anti-estatismo libertario, centrado en la organización sindical y la propaganda y agitación anarquista.

En dicho proceso, que duró algunos años (entre 1905 y 1908), sus menciones en torno a la historia paraguaya reciente fueron cambiando de tono: de aquellas primeras referencias a las "tiranías" pasaría a recuperar a la "fuerte y hermosa raza" paraguaya de antes de la guerra, cuya hidalguía y nobleza percibió en su contacto con los "veteranos del 70 ", los pocos sobrevivientes de la catástrofe: "Viejo, setenta años; pero un viejo fuerte, 
de la hermosa y casi desaparecida raza paraguaya de hace medio siglo" (Barrett: 1911, 83). La recuperación de los "veteranos" no le impidió seguir manteniendo una distancia con el "tirano" López: "aquel hombre siniestro, a quien se puede aborrecer, pero no achicar", cuya sombra "oscurece la conciencia de los viejos y tal vez ha impregnado la sangre de los niños" (83). El hecho de que registre una "entrevista" con un desertor que, para salvar la vida, había abandonado el ejército de López antes del final, es una muestra evidente de que su rescate no se encontraba en la órbita de la idealización patriótica.

$\mathrm{Su}$ interpretación de la guerra también cambiaría radicalmente. En un artículo publicado en Rojo y Azul el 1ro. de diciembre de 1907, elaboraría ya una compleja explicación de sus nefastos efectos en las décadas posteriores:

Por una fatal excepción la guerra no solamente asoló y ensangrentó al país, sino que lo degeneró por mucho tiempo. Lo castró al destruir los gérmenes de aquella hermosa raza, resplandeciente todavía en las nobles figuras de los viejos que sobreviven. Las generaciones posteriores se tallaron en otra madera. (...) Fueron una casta distinta, inferior; otra nación improvisada, soldada de cualquier modo a la antigua (Barrett: 1911, 116-117).

El acercamiento a la miserable realidad campesina también lo llevaría a asumir una posición de denuncia cada vez más abierta de los abusos y atropellos de terratenientes, caudillos, políticos y "letrados": muchos de ellos corruptos que, oficialmente, se sumaban a la prédica "cretinista". En efecto, estas tesis cretinistas eran frecuentemente utilizadas, tanto por autores locales como por inversores extranjeros, en justificación del progresivo desarrollo de un marco jurídico-legal que tendía a la desposesión del campesinado paraguayo -incapaz según sus referentes de transformarse en una burguesía rural- y al sostenimiento de prácticas de sujeción extraeconómica y disciplinamiento de los trabajadores paraguayos, que según estos autores, por su "natural indolencia" debían ser sometidos a formas coercitivas de trabajo ${ }^{15}$.

Más que en la figura de López, que nunca reivindicaría, el cambio en su interpretación de la guerra del Paraguay puede ser mejor percibido siguiendo las opiniones que le merecía Bartolomé Mitre. A raíz de su muerte, en 1906, Barrett escribió una elogiosa nota, titulada "El hombre-nación", en donde lo llamaba "jefe espiritual de su patria". Influenciado por Carlyle, destacaba la importancia de los "héroes" en determinados momentos de la historia, y puntualizaba que Mitre había sido el héroe nacional argentino: "Llena él solo la historia, y es la primera historia con que se fecunda la inteligencia de los niños. Ejemplo perpetuo de grandeza, excitante universal de energías, poeta y epopeya a la vez, muere gloriosamente, para reinar, como

${ }^{15}$ El mismo José S. Decoud (1877) sostenía que "durante el largo reinado de la tiranía fue necesario dictar medidas rigurosas para obligar a los naturales á hacer plantaciones" (4). Estas ideas fueron la base de disposiciones, leyes y decretos que establecían la "esclavitud por deudas" (decreto de 1871. en Barrett, 1988), así como sucesivas leyes que penalizaban la "vagancia". 
Castells. Política e Historia: Rafael Barret y una tercera mirada en las polémicas sobre el pasado y el presente en...

Dios, invisible" (Barrett: 1990, 104'6). Apenas dos años después, de esas elogiosas expresiones pasamos al desprecio más absoluto. En un artículo titulado "La historia y el éxito" (El Diario, 4 de abril de 1908), recordando su tratamiento anterior, se preguntaba qué era lo que había llevado a Mitre a transformarse en el "hombre-nación" a pesar de sus "discretas dotes". Seguidamente se respondía: "Mitre encarna el éxito. Por eso es el Washington de por acá, el Hombre-Nación. Si López hubiera triunfado, lo que no era tan imposible, hubiera sido nuestro Washington, nuestro Mitre, y a Mitre le hubiera solamente salvado del olvido su chistosa traducción de Dante" (Barrett: 1989, 86).

¿Qué lo llevó a cambiar de opinión tan rápidamente? El quiebre, a nuestro entender, se produce a inicios de 1908, cuando se asume como anarquista y comienza su campaña de denuncias en la prensa. Desde aquí en adelante, y de acuerdo con el tono de las mismas, la "tiranía" de López pierde todo matiz original y pasa a ser común a la opresión política en general, incluyendo como vemos a Mitre (en ese artículo de 1908), al que considera "un déspota militar" rodeado de criminales de reconocida brutalidad (Barrett: 1989, 86). En aquel momento, además, era presidente del Paraguay, y objeto de sus denuncias, Benigno A. Ferreira: un antiguo legionario, liberal cívico y reconocido "antilopista" ${ }^{17}$. Por otro lado, puede que haya influido en su cambio de opinión la figura del Padre Fidel Maíz, tío de su esposa, Francisca "Panchita" López Maíz, antiguo "fiscal de sangre" y colaborador de López, quién fue uno de los primeros críticos de las tesis cretinistas y a quién Barrett frecuentaba ${ }^{18}$. También podemos pensar en que sus ideas no se alejaban mucho de las que expresaban sus amistades liberales más cercanas, como Alejandro Audibert (su concuñado) y Manuel Gondra ${ }^{19}$. En fin, otras fuentes importantes, y mencionadas por él mismo, son la obra del anarquista francés Elisée Reclus y del intelectual liberal argentino Juan B. Alberdi.

La rivalidad entre este último autor y Mitre son sobradamente conocidas, y la guerra del Paraguay fue uno de los acontecimientos que más la expresaron. Barrett, de formación liberal, pasó a reivindicar la figura de Alberdi, en desmedro de la de Mitre, coincidiendo aquí, curiosamente, con Juan E. O’Leary. Hacia 1910, comentando los términos en que el diario La Nación de Buenos Aires denostaba a Alberdi y ensalzaba a Mitre, Barrett tomaba

\footnotetext{
${ }^{16}$ En la recopilación de sus Obras Completas, no hay datos sobre la publicación original de este texto, sólo que fue publicado como una especie de necrológica. Por los datos que manejamos, la fecha y el contenido de la publicación, posiblemente haya sido publicada en El Cívico, órgano liberal donde Barrett estaba colaborando en esos momentos.

${ }^{17}$ Para entonces, los políticos paraguayos de todas las tendencias eran para Barrett, una banda "de tahúres y bandoleros" (Germinal, 2 de agosto de 1908, No 1, en Barrett, 1990, 211).

${ }^{18}$ En una obra de índole educativa publicada en 1887, "Pequeña Geografía para los niños de la Escuela de Arroyos y Esteros”, el P. Maíz denunciaba las tesis cretinistas en boga: “Cómo nutrir, pero ni despertar estos sentimientos [de patriotismo] en los tiernos corazones de nuestros educandos por medio de textos de Geografía y de Historia, en que se nos pinta con colores tan sombríos, en que se nos trata de autómatas paraguayos, en que no se nos reserva ni siquiera el heroísmo del valor y del patriotismo, y se nos enrostra siempre la culpa de haber tenido tiranos, como si ellos no los hubieran tenido también?" (citado en Velázquez Seiferheld: 2015, 98).

${ }^{19}$ En 1919, en otro contexto del Paraguay, los liberales radicales vinculados a Gondra participarían en otra polémica sobre el "lopismo", esta vez enfrentándose en una interna dentro del mismo Partido Liberal, desde los periódicos El Diario y El Liberal. Véase Orué Pozzo, 2008.
} 
el camino opuesto, y el tono apologético recaía ahora en el tucumano, al que consideraba "un genio universal". De Mitre, por el contrario, recuperaba un texto infame, que defendía los "derechos por victoria militar". Opinaba, entonces:

Prefiero a cualquier sainete el espectáculo del excelente general Mitre, en sus tentativas desesperadas para pensar. Su tesis es que la victoria da derechos. Al más tonto se le ocurre que si ningún escrúpulo legítimo debe detener al vencedor, sólo por serlo, y la victoria da el derecho, es que no lo había antes de emprender la guerra, y por lo tanto se trata de una guerra inicua. Mitre no ve el sofisma. Dios no concedió a este honesto soldado el ingenio filosófico. Recorred sus obras literarias; son un desierto espiritual y una metrópoli de lugares comunes. ¡Noble Alberdi! ¿Qué gallos echan a reñir con los tuyos! Pero el futuro te vengará. El que osó en la portada de la traducción de La Divina Comedia enlazar su perfil al de Dante por una misma rama de laurel, será pronto alejado de tu sagrada tumba ("Carta de un viajero", septiembre de 1910, recuperada en Barrett, 1989, 155).

Es comentando la obra del geógrafo anarquista francés ${ }^{20}$ que, no obstante, Barrett expresa su rechazo de las tesis cretinistas. Reclus sostenía que la magnitud del crimen transformaba en "vergonzoso" el triunfo de los aliados, perpetradores de dicha masacre. Barrett, sin embargo, ironizaba y apelaba a la identificación que el cretinismo tenía con los vencedores:

No, ingenuo sabio. Lo vergonzoso es la derrota. El triunfo es la virtud. La Historia, como la sociedad, adora cobardemente el éxito. Buen Reclus, eres un furioso lopista. Hoy, la opinión oficial es, hasta en el mismo Paraguay, que los aliados vinieron a civilizarlo, a sacarlo de la tiranía. Los soldados de López, las mujeres y muchachos que dejaron en la madre tierra las barricadas de sus huesos, no eran más que unos cretinos [...] ...la Argentina se consagró a civilizar a cañonazos el Paraguay. En la Argentina no había seguramente cretinos. ¿Por qué? Porque venció (Barrett 1989, 85).

Más allá de estas menciones históricas, el principal objetivo de Barrett se centraba en la denuncia del estado miserable de la población paraguaya contemporánea, constituida por un "vasto hospital de alucinados y melancólicos". Debido a esta denuncia, no tardó en entrar en dura polémica con quiénes negaban dicha situación.

\footnotetext{
${ }^{20}$ Se trata de un artículo de Elisée Reclus, titulado "Les Républiques de l'Amérique du Sud, leurs guerres et leur projet de fédération", publicado en la Revue des deux mondes, octubre de 1868. Ideas semejantes fueron publicados en su "Nueva Geografía Univeral", cuyos capítulos dedicados a Paraguay fueron traducidos y editados por A. de Uribe y Cía, en Asunción, 1896. Véase Rivarola (1988).
} 
Castells. Política e Historia: Rafael Barret y una tercera mirada en las polémicas sobre el pasado y el presente en...

La principal polémica se dio en el año 1910, a raíz de la publicación de Barrett de un artículo titulado "Lo que he visto" (El Nacional, 21 de febrero de 1910), en donde denunciaba la miserable situación de la sociedad campesina paraguaya, una "raza" que se encontraba enferma, fruto de la brutal explotación de la que era objeto:

En un año de campaña paraguaya, he visto muchas cosas tristes...

He visto los viejos caminos que abrió la tiranía devorados por la vegetación, desleídos por la inundación, borrados por el abandono. Cada paraguayo, libre dentro de una hoja de papel constitucional, es hoy un miserable prisionero de un palmo de tierra (...)

He visto que no se trabaja, que no se puede trabajar, porque los cuerpos están enfermos, porque las almas están muertas. He visto que los peones "robustos" no pasan dos semanas sin algún día de diarrea o fiebre. iPobre carne, herida hasta en el sexo, pobre carne morena y marchita, desarmada de toda higiene, sin más ayuda exterior que el veneno del curandero, el rebenque del jefe político, el sable que les arrea al cuartel gubernista o revolucionario! (...)

$Y$ he visto en la capital la cosa más triste. No he hallado médicos del alma y del cuerpo de la nación; he visto políticos y comerciantes. He visto manipuladores de emisiones y de empréstitos, boticarios que se preparan a vender al moribundo las últimas inyecciones de morfina... (Barrett: 1911, 95-97).

Quiénes se sintieron más tocados por esta denuncia fueron los novecentistas, que tendían a idealizar en cuadros costumbristas la vida rural paraguaya. La respuesta provendría de la pluma de Manuel Domínguez, quien bajo el seudónimo de Juvenal, en el mismo periódico escribiría el artículo "Lo que Barrett no ha visto", en donde sostenía que éste, "creyendo pintar al Paraguay, sólo acierta á pintarse a sí mismo", acusándolo de ver el Paraguay con sus ojos de enfermo, sin entender las peculiaridades de la humilde vida campesina. La argumentación de Domínguez se sostenía en el mismo tono de la polémica planteada en 1902 con Báez. Planteaba que Barrett veía, condicionado por su enfermedad, "pobreza y miseria" en dónde lo que había en realidad era "sencillez", siendo su visión parcial y, por ende, "falsa":

Observó durante un año y concluye caritativamente por graduar al Paraguay con el rótulo infamante del país más desgraciado del universo (...) Barrett ha visto casi nada. Vió Yabebiry y las orillas desiertas y risueñas del río, marchando en el vapor. Quizá, á lo más, estuvo en casa de algunos pordioseros y por la clorósis ó la palidez podrida de estos míseros juzga á la República. Del bosquejo de este pintor audaz y falso, sale que 


\section{el Paraguay es una enfermería de hambrientos en inminente podredumbre. \\ Manuel Domínguez a.k.a. Juvenal, "Lo que Barrett no ha visto", El Nacional, Asunción, 22 de febrero de 1910 (Biblioteca Nacional del Paraguay).}

Lo acusa, además de pintar trágicamente la realidad con la intención de crear "frases de efecto" que nada tenían que ver con la situación del Paraguay, abusando de "colores fuertes" en que "el vulgo ve estelas de genio" sin recabar en que de esa manera estaba deshonrando a un país.

La polémica llevaría dos artículos más, "No mintáis" de Barrett y la respuesta "Distinguid" de Domínguez, fechada el 7 de marzo de 1910. El trasfondo se encontraba obviamente en el contraste entre la realidad denunciada por Rafael Barrett y la idealización romántica a la que tendían las obras de Manuel Domínguez y Juan O'Leary. Pero bajo esta "idealización" se encontraba, además, una defensa indiscutible del statu quo oligárquico y latifundista. La respuesta de Domínguez también se inscribía en el plano de una sólida barrera de clase. No es inocente su posición al respecto: en la misma conferencia de 1903 donde hablaba de la superioridad de la "raza paraguaya", comentaba que "el peón de ahora, medio anémico o anémico entero, algunas veces alcoholizado, cuando no le falte el locro es de una increíble resistencia". Planteaba además que no era casualidad que las empresas latifundistas prefirieran la mano de obra paraguaya, más resistente a las de sus vecinos:

“¿Dónde recluta peones la Compañía Matte Larangeira?

En el Paraguay. Aquello revienta a cualquiera que no sea paraguayo (...) Sólo el paraguayo puede con el pesado trabajo de los yerbales y el obraje” (Domínguez: 1903, 21).

Domínguez se alejaba de esta manera del "cretinismo", que postulaba la "indolencia natural" del paraguayo, pero en lugar de denunciar la explotación descarnada de los peones, esclavizados en los yerbales -como denunció Barrett (1988 [edición original en 1908] ${ }^{21}$ )-, Domínguez alababa su resistencia física. Cómo plantea Telesca (2012), "tras esa imagen de la raza paraguaya no sólo se justifica una historia heroica sino también una situación social de exclusión” (141).

Sobre la defensa del statu quo y la idealización del pueblo por parte de Domínguez pasaría la respuesta de Barrett. En "No mintáis" (El Nacional, 5 de marzo de 1910), apuntaría de manera colectiva a los novecentistas en su "cómoda" posición de intelectuales de la clase dominante, que idealizaban al pueblo pobre, banalizando su situación, sin padecer sus mismas penurias:

No mintáis, hermanos.

Si vivis en la ciudad donde hombres con zapatos de charol

21 "Lo que son los yerbales" fue publicado, en cinco entregas, en El Diario, entre el 15 y el 27 de junio de 1908. En 1910 se publicaron como folleto por Bertani Editor, en Montevideo. 


\section{ARTÍCULOS}

Castells. Política e Historia: Rafael Barret y una tercera mirada en las polémicas sobre el pasado y el presente en...

y cuellos planchados manejan el dinero de las aduanas, no digáis que los que andan descalzos y medio desnudos son felices, porque no lo son.

Si habitáis en casas de ladrillos y de piedra, con vidrios en las ventanas y puertas que ajustan, no digáis que están contentos los pobres en sus escondrijos de barro, porque no lo están.

Si os conducen de una parte a otra en ferrocarril o en tramway, no digáis que los rastros de bestias en que el campesino hunde sus pies fatigados son satisfactorios, porque no lo son.

Si coméis pan blando, carne bien guisada, y bebéis vino perfumado, no entonéis himno de alabanza al inmundo locro de los ranchos, porque mentis.

No mintáis, graves doctores, hermanos míos. (...) Hablad de vuestros honorarios, de vuestros expedientes, de vuestros informes sesudos, de folletitos académicos que os dedicáis llamándoos ilustres, insignes y salvadores de la patria. Hablad de vuestros pleitos. Hablad de política. No habléis del pueblo. No.

Pero si queréis ver a ese pueblo, cara a cara, si queréis tocar y oler esa carne que suda y que sufre, no tenéis necesidad, no, de que yo os lleve a las soledades de Yabebyry. Id a vuestra cocina, oh doctores, y alli encontraréis alguna sierva que os lava platos y lame vuestras sobras. Preguntadla cómo se alimenta "el pueblo soberano" y cómo vive. Preguntadla por la salud de sus hijos, y si sus hijos pueden contestar, preguntadles quién fue su padre (Barrett: 1988, 176).

La réplica definitiva de Domínguez derivaría en la típica reacción de las élites políticas latinoamericanas ante los extranjeros "críticos"22. En dicho artículo distinguiría tres tipos de extranjeros: los sabios (que ayudan a "encontrar la verdad"), los trabajadores (que contribuyen con su trabajo e industria al engrandecimiento del país) y los indeseables, que "se dicen críticos"; que no estudian ni observan con la modestia en que deberían hacerlo, como lo hacen los sabios; sino que declaman y afrentan buscando deshonrarse "por el afán curioso de brillar en el papel”. Ubicaba, claramente, a Barrett como el típico extranjero indeseable, que no viene a aportar su pluma o su industria al

\footnotetext{
${ }^{22}$ Si bien el caso de Barrett es bastante particular por su condición de intelectual (aunque también era un "agitador" anarquista), no deja de ser otra expresión del rechazo que las élites latinoamericanas tenían hacia ciertos extranjeros "indeseables", sobre todo dirigentes obreros socialistas y anarquistas. Este rechazo no era incompatible con su ideal de fomento de la inmigración extranjera, que se seguía defendiendo como apuesta civilizatoria. En este sentido y cómo ejemplo de esto, vale seguir el debate realizado en el Congreso argentino (y en la prensa liberal) con motivo de la sanción de la Ley de Residencia, los argumentos allí utilizados son similares. La bibliografía sobre el tema es abundante, para el rápido debate dado en el recinto, véase, Diario de Sesiones, 22 de noviembre de 1902; para la cobertura en el diario La Nación, véase Arecco (2007).
} 
beneficio del país receptor, sino a contribuir a "desacreditarlo"23. En esta respuesta, se puede vislumbrar una ruptura profunda y definitiva entre ambos polemistas, que hasta ese entonces gozaban de una buena relación ${ }^{24}$.

Efectivamente, la crítica social de Barrett generaría una antipatía duradera en los novecentistas, que se prolongaría en el tiempo hasta mucho después de su muerte. Todavía en 1925, al escribir el prólogo a Guaranies, libro de Martín Goicoechea Menéndez, escritor argentino que visitó el Paraguay a principios de siglo, O’Leary trazaba una comparación entre ambos extranjeros.

Goicoechea Menéndez (1875-1906) había llegado al Paraguay en 1901, trabando amistad con varios de los miembros de la generación novecentista, incluidos O'Leary y Domínguez. Allí coincidió con Rafael Barrett, de quién guardaría buena memoria ${ }^{25}$. Casi de la misma edad, Goicoechea también moriría joven, en 1906 víctima del tifus en Yucatán, México. Un año antes de su muerte, publicaría en Asunción un libro titulado Cuentos de los héroes y de las selvas guaranies, que incluía un poema en prosa titulado "La noche antes", en el que recreaba los sentimientos y acciones de Francisco Solano López en la víspera de su muerte en Cerro Corá, la última batalla de la guerra. Este libro tendría un impacto fundamental en el romanticismo de los novecentistas, "ya que recreaba la epopeya de un pueblo y la tragedia de un hombre que encarnó ese pueblo" (Brezzo: 2008, 25), ejerciendo gran influencia en la narrativa del mismo O'Leary. Decía éste que, siendo ambos extranjeros, a Goicoechea Menéndez se le admiraba "pero más se le quería", contrariamente a Barrett, "que pudo ser admirado, pero no llegó a ser amado". Planteaba que entre uno y otro hubo una inmensa "distancia moral":

Goicoechea era un sensitivo, que comprendía los dolores del Paraguay y sentía la realidad afectiva del ser espiritual del paraguayo; mientras que Barrett, al contrario, era un "puro cerebral" que, secas las fuentes de su corazón, dominado por su tragedia personal, "veía nuestras cosas con sus ojos huraños de europeo y de enfermo, atribuyéndonos, como le dijo una vez el gran Domínguez, sus propias miserias". Y así, mientras del uno quedan páginas maravillosas, impregnadas de amor, verdaderas adivinaciones de nuestros sentimientos, evocaciones magníficas de nuestra historia, cuadros llenos de realidad de nuestras costumbres, páginas de un sano optimismo que han de fortificar siempre nuestra fe en los destinos de

${ }^{23}$ Manuel Domínguez a.k.a. Juvenal, "Distinguid”, El Nacional, Asunción, 22 de febrero de 1910 (Biblioteca Nacional del Paraguay).

${ }^{24}$ En efecto, Barrett había escrito una breve semblanza apologética, titulada "Manuel Domínguez", del que desconocemos los datos de su publicación original. Allí Barrett (1989) dice de aquel: "es imposible dejar de admirar su genio vigoroso y su erudición honda y hábil, y es también imposible dejar de amar su buen corazón, abierto siempre al amigo como un refugio hospitalario" (132).

${ }^{25}$ Raúl Amaral da cuenta de una carta que, desde París, Goicoechea Menéndez le manda a su amigo Modesto Guggiari, en donde le recomienda que salude especialmente a Rafael Barrett de su parte (Goicoechea Ménendez: 1985, 115). 
Castells. Política e Historia: Rafael Barret y una tercera mirada en las polémicas sobre el pasado y el presente en...

nuestra raza, que han de levantar nuestro espíritu, poniendo una nota perenne de luz en nuestro camino; mientras que del otro no nos quedan sino las exageraciones sombrías de su pesimismo, los cuadros tristes de lo que él llamaba "el dolor paraguayo", y no eran sino los desahogos de su melancolía, indiferente a todas las manifestaciones del mundo exterior, a pesar del empeño que mostraba en aparecer preocupado de los problemas y de los incidentes de la vida nacional. (O'Leary: 1925, XXII-XXIII)

Las preferencias de O’Leary y Domínguez eran puramente políticas. Las páginas de Goicoechea Menéndez representaban un cuadro pintoresco del paisaje y del pueblo paraguayos, que para nada resultaban ofensivos ante la vista de los novecentistas. Goicoechea, además, reivindicaba las figuras de los héroes paraguayos del siglo XIX y el "heroísmo desgraciado" del país, poniéndose en el mismo plano de la prédica del discurso patriótico que O’Leary venía proponiendo. El "crítico" Barrett, al contrario, era considerado un "puro cerebral", un analista alejado de las vivencias del pueblo y, por ende, se le negaba toda autoridad a sus palabras en defensa de los humildes.

Barrett había muerto quince años antes, pero uno de los principales defensores de su obra, el intelectual comunista argentino Álvaro Yunque (1929), comentaría indignado las palabras de O’Leary: “¡Barrett indiferente a las manifestaciones del mundo exterior, cuando vivió desbordándose sobre él! ¡Barrett 'huraño europeo', cuando fue todo cordialidad para los que sufrían! Ocurre que Goicoechea es un literato, nada más. Vio lo pintoresco de la raza y la naturaleza del Paraguay". Aclararía, además, yendo al meollo de la cuestión, que Goicoechea había evocado la historia del Paraguay "con criterio de patriotero paraguayo". En definitiva, planteaba Yunque:

Los patriotas -a lo O'Leary o Domínguez, que viven de embrutecer a sus semejantes- por fuerza debían negar a Barrett. Él era enemigo, en tanto que Goicoechea, literato fácil que se detuvo en lo superficialmente pintoresco, les venía a resultar, sin él quererlo, un aliado eficaz. Éste lo embadurnaba todo con brillantes pinceladas de sentimentalismo. Barrett en cambio, hacía saltar el barniz de las palabras con que los Domínguez o los O'Leary pretendían cubrir el dolor de esa misma raza a la que ellos enaltecían como soldados para explotarla como obreros $(1929,14-15)$.

La denuncia social de Barrett implicaba un programa de acción determinado. Alejado de las ideas de construir o fortalecer una identidad nacional o fomentar el patriotismo, su preocupación era educativa, pero se trataba de una educación muy diferente a la propuesta cívica de los cretinistas. Al igual que éstos, denunciaba el autoritarismo y las miserables condiciones en que vivía el pueblo paraguayo, pero 
se diferenciaba de ellos, al abandonar toda prédica "civilizatoria". Su romanticismo anticapitalista no sólo desconfiaba, sino que denunciaba la "civilización":

"El Paraguay es un vasto hospital de alucinados y de melancólicos. No son oradores ni capitalistas ni sargentos lo que nos hace falta, sino médicos, médicos amorosos cuyas manos a un tiempo curen y acaricien" (Barrett: 1911, 119).

La referencia a "alucinados y melancólicos" puede hacernos pensar en una fórmula cercana al cretinismo, pero sólo comparte con ellos parte del balance (la situación miserable y de "resignación" ante la opresión es, en gran parte, explicada por la guerra más que por la tiranía). Adecuada a sus reflexiones filosóficas, cercanas al "vitalismo" de aquellos años (Nietzsche, Bergson, etc.), en un artículo titulado "La Verdad", comentaría que el Paraguay sufría lo que llamaba una "depresión moral", originada por la derrota y la miseria subsecuente, que había generado una especie de sentimiento de inferioridad que le sublevaba notoriamente: "Yo quiero que esta tierra donde han de nacer mis hijos sea un día grande y dichosa. Yo quiero para ella, mejor que ejércitos y exportación, lo que deseo para mí, lo que palpita en todo ser superior a su destino: el orgullo" (Barrett: 1988, 160). Es decir, para los desheredados, aplastados por una guerra total y por gobiernos antipopulares después, lo que pide es fuerza para luchar, para sobreponerse y pelear por sus derechos.

Consideraba, entonces, que el pueblo paraguayo era un pueblo enfermo y "doliente": hogares heridos ("sin padre"), violencia política, servidumbre femenina, manipulación patriótica, disciplinamiento militar, trabajo esclavo, mortalidad infantil, etc. ${ }^{26}$ Ante esta situación, no se necesitaban escuelas, elecciones, disciplina de trabajo y ahorro, sino militancia social, organización y ayuda mutua: "universitarios que proyectáis regeneraciones, retóricos del sacrificio, abandonad esa colmena central y dispersaos por los modestos rincones de vuestro país, no para chupar sus jugos a los cálices ingenuos, sino para distribuir la miel de vuestra fraternidad" (Barrett: 1988, 10). Como buen anarquista, y además tolstoiano, la "práctica de la libertad" para Barrett nada tenía que ver con las instituciones del estado y sí, mucho, con el altruismo y la solidaridad.

\section{Consideraciones finales}

Como vemos, en esta serie de polémicas acontecidas entre 1902 y 1910, la historia paraguaya se ubicó en el centro de la escena, poniendo al descubierto distintas maneras de pensar el pasado en relación con las tareas pendientes en el presente: problema particularmente importante en el contexto de crisis social y política del primer centenario de las independencias hispanoamericanas. Allí se explicitaron las dos grandes matrices narrativas que dominarían la representación del pasado en el Paraguay por mucho tiempo: la liberal-positivista y la romántico-nacionalista. Se trataba de dos formas diferentes de pensar la historia que, a su vez, manifestaban dos proyectos

\footnotetext{
${ }^{26}$ Tales son algunos de los temas abarcados por sus artículos incluidos en su compilación titulada El Dolor
} Paraguayo (Barrett, 1911). 
Castells. Política e Historia: Rafael Barret y una tercera mirada en las polémicas sobre el pasado y el presente en...

distintos de construcción de la nación desde la élite dirigente. A la élite paraguaya de la posguerra, que tuvo que hacerse cargo de un país destruido, se le presentó el desafío de reconstruir una nación sobre bases completamente distintas a las del período anterior al conflicto. Para esta primera generación de intelectuales, entre los que se contaba Báez, formados precisamente en oposición a la tradición "autoritaria" del siglo XIX que tanto habían combatido, la "nación" debía ser construida desde cero, renunciando y negando el proyecto de construcción nacional anterior a la guerra. Para ellos, había que negar al Paraguay del siglo XIX (dictadura de Francia y gobiernos de los López), y formar, a partir de la tabula rasa que eran los escombros del Paraguay del novecientos una nueva sociedad, siguiendo el modelo europeo, moderno, liberal, "civilizado". De ahí el encono que pusieron en perseguir aquellos rasgos de la sociedad que consideraban como supervivencias de la barbarie: el idioma guaraní, el cretinismo del pueblo, y en menor medida, la cultura política autoritaria, la religiosidad popular, etc.

En oposición a esta vertiente ideológica, al servicio de la reconfiguración socioeconómica y geopolítica del país en la inmediata posguerra (llamada por sus epígonos, "regeneración"), algunos intelectuales de la generación "novecentista" no tardaron en "recuperar" justamente aquellos rasgos que sus adversarios denostaban. Juan O'Leary y Manuel Domínguez comenzaron a idealizar el Paraguay previo a la guerra y a construir el mito de una "edad de oro". Se trataba de los comienzos de una paulatina reivindicación del Paraguay del siglo XIX y de sus gobernantes, que se fue consolidando mientras más alejada se encontraba aquella realidad. Esta reivindicación se hacía claramente extensible hasta el presente de la polémica, negando la "cuestión social" y redundando en una defensa del régimen oligárquico-latifundista.

A contramano de ambas posiciones, y desde su lugar marginal como vocero del naciente movimiento obrero paraguayo, fue Rafael Barrett quien precisamente planteó en sus escritos una tercera mirada del pasado paraguayo. Denunció las tesis cretinistas a las que identificó como la versión de los vencedores, pero se distanció de la idealización romántica de los novecentistas, denunciando su vinculación a la clase dominante y su justificación de la opresión y explotación de obreros y campesinos del presente. Su posición derivó en una clara reivindicación del pueblo paraguayo masacrado, valorando su resistencia, su valor, su heroísmo; sin por eso dejar de denunciar "que no se obedeció a López impunemente" y que el pueblo paraguayo tuvo que cargar sobre sus espaldas las locuras de su gobernante.

Planteaba que, lejos de ser un pueblo cretino, el pueblo paraguayo del tiempo de López era superior al de la época liberal, quedando manifestado en la gallardía de los pocos veteranos que sobrevivían. El "cretinismo", que tendrá una presencia menor en la obra barrettiana, en su argumentación se correspondería al Paraguay liberal, y dicha condición era explicada como resultado de la particular tragedia de un pueblo nacido de una derrota terrible, al que era necesario "curar" y no "civilizar". Esta visión "desde abajo" fue dejada de lado y apenas pudo competir con las otras dos grandes narrativas.

Desde los años treinta, y en vinculación directa a la emergencia de gobiernos antiliberales y nacionalistas luego de la guerra del Chaco (1932-1935), el relato heroico se 
transformó en predominante reemplazando la ya caduca visión "cretinista", relegados sus representantes a la condición de "legionarios", es decir, traidores a la patria (Capdevila, 2010; Fuentes Armadans, 2016). Desde las últimas décadas, y sobre todo luego de la caída de Alfredo Stroessner, el discurso nacionalista, oficial en tiempos de la dictadura, comenzó a ser sometido a una dura crítica, aunque, como muchas otras reminiscencias del periodo dictatorial, continúa teniendo un enorme vigor. En este panorama, el rescate de la denuncia de Barrett, entendiéndola no cómo no sólo como una versión alternativa de los relatos dominantes sino, y principalmente, como un ejercicio de reflexión crítica distanciada de ellos y de sus premisas políticas (más o menos evidentes), nos parece un ejercicio fundamental en vistas de la tarea de construcción de nuevas producciones historiográficas, con nuevos enfoques, preguntas y procedimientos.

\section{Referencias bibliográficas}

Altamirano, C. (2008). Historia de los intelectuales en América Latina, vol. 1. Buenos Aires: Katz Editores.

Amaral, R. (2006). El novecentismo paraguayo. Asunción: Servilibro.

Archivo del Liberalismo (1988). "El Mariscal López. Una sesión histórica en la Cámara de Diputados 31 de agosto de 1926”. Cuadernos Históricos 4, Asunción: Archivos del Liberalismo.

Arecco, M. (2007). "La construcción de obreros argentinos. El diario La Nación y la Ley de Residencia”. VII Jornadas de Sociología. Facultad de Ciencias Sociales, Universidad de Buenos Aires, Buenos Aires.

Báez, C. (1903). La tiranía en el Paraguay: sus causas, caracteres y resultados. Asunción: Tipografía El País.

Báez, C. (1906). Cuadros históricos y descriptivos. Asunción: Talleres H. Kraus.

Báez, C. \& O’Leary, J. (2008). Polémica sobre la historia del Paraguay. Asunción: Tiempo de Historia.

Báez, C. (2013). Escritos Selectos. Asunción: Biblioteca Nacional del Paraguay.

Barrett, R. (1911). El dolor paraguayo. Montevideo, Uruguay: Bertani.

Barrett, R. (1988). Obras Completas I - II. Asunción: ICI - RP Ediciones.

Barrett, R. (1989). Obras Completas III. Asunción: ICI - RP Ediciones.

Barrett, R. (1990). Obras Completas IV. Asunción: ICI - RP Ediciones.

Boidin, C. (2006). "Pour une anthropologie et une histoire régressive de la Guerre de la Triple Alliance", Nuevo Mundo Mundos Nuevos, Coloquios, Puesto en línea el 20 de marzo de 2006. URL: http://nuevomundo.revues.org/index2061.html

Brezzo, L. (2008). "En el mundo de Ariadna y Penélope. Hilos, tejidos y urdimbre del nacimiento de la Historia en el Paraguay". Ensayo introductorio de C. Báez \& J. O’Leary, Polémica sobre la historia del Paraguay. Asunción: Tiempo de Historia.

Brezzo, L. (2009). “¿La gran polémica continua!”, en Nuevo Mundo Mundos Nuevos, Coloquios, Recuperado de: http://nuevomundo.revues.org /index48832.html

Brezzo, L. (2010). El Paraguay a comienzos del siglo XX (1900-1930). Asunción: El Lector. Colección La Gran Historia del Paraguay, 9. 
Castells. Política e Historia: Rafael Barret y una tercera mirada en las polémicas sobre el pasado y el presente en...

Brezzo, L. (2015). La Guerra del Paraguay en primera persona. Testimonios inéditos. Fondo Estanislao Zeballos. Asunción: Tiempo de Historia.

Capdevila, L. (2010). Una guerra total: Paraguay 1864-1870. Buenos Aires: SB (Paradigma Indicial).

Decoud, J. (1877). Cuestiones politicas y económicas. Asunción: Imprenta de "La Reforma". Domínguez, M. (1903). Causas del heroísmo paraguayo. Asunción: Talleres Nacionales de H. Krauss.

Domínguez, M. (2009). El alma de la raza. Asunción: Servilibro.

Fuentes Armadans, C. (2016). La maldición del legionario. Asunción: Tiempo de Historia. Gaona, F. (2008). Introducción a la historia gremial y social del Paraguay. Tomo 1. Asunción: Germinal / Arandurã Editorial.

Goicoechea Menéndez, M. (1985). La noche antes: antología paraguaya (1901-1905). Asunción: Alcándara. Edición a cargo de Raúl Amaral. También hay edición digital: Alicante, Biblioteca Virtual Miguel de Cervantes (2000).

Kleinpenning, J. (2014). Paraguay rural 1870-1963. Una geografía del progreso, el pillaje y la pobreza. Asunción: Tiempo de Historia.

Langa Pizarro, M. (2006). "La guerra de la Triple Alianza en la literatura", Nuevo Mundo Mundos Nuevos, Coloquios, Recuperado de: http://journals.openedition. org/nuevomundo/1623.

Martínez, V. (2018). La vida es tempestad. Historia de la familia Barrett: Literatura, resistencia y revolución. Asunción: Arandurã Editorial.

O’ Leary, J. (1925). “Martín de Goicoechea Menéndez”, prólogo a Martín Goicoechea Menéndez. Cuentos de los héroes y las selvas guaranies. Asunción: Imprenta Ariel.

O’ Leary, J. (2008). Recuerdos de gloria. Asunción: Servilibro.

Orué Pozzo, A. (2008). Periodismo y Nación. Paraguay a inicios del siglo XX. Asunción: Arandurã Editorial.

Rivarola, M. (1988). La polémica francesa sobre la guerra grande. Asunción: Editorial histórica.

Rivarola, M. (2010). Obreros, utopías \& revoluciones. Asunción: Servilibro.

Sarah, D. (2011). "Prólogo" a Mauricio Schvartzman. Contribuciones al estudio de la sociedad paraguaya. Asunción: Secretaría Nacional de Cultura.

Sarmiento, D. (1915 [1883]), Conflicto y armonía de razas en América. Buenos Aires: La Cultura Argentina.

Telesca, I. (2012). "El debate Domínguez-Barrett. Implicancias sociales de la idea de 'nación mestiza'”. En: Revista Paraguaya de Sociología, n 141, pp. 233-242.

Telesca, I. (2013). “La historiografía producida en el Paraguay durante el último quinquenio". En: Jahrbuch für Geschichte Lateinamerikas, vol. 50, Issue 1, pp. 375-385.

Velázquez Seiferheld, D. (2015). Relaciones entre autoritarismo y educación en el Paraguay, 1869-2012. Un análisis histórico. Vol. 1 1869-1930. Asunción: SERPAJ.

Yunque, A. (1929). Barrett: su vida, su obra. Buenos Aires: Claridad. 